\title{
Can new technology challenge macho-masculinities? The case of the mining industry
}

\author{
Lena Abrahamsson ${ }^{1}$ (D) Jan Johansson ${ }^{1}$ (D) \\ Received: 7 December 2019 / Accepted: 27 March 2020 / Published online: 29 April 2020 \\ (C) The Author(s) 2020
}

\begin{abstract}
The aim with this article is to discuss how changes in technology at workplaces engender both change and restoration of gender constructions within the context of underground mining. The discussions are formed around a constructed case based on material from gender and organizational studies of large-scale industrial mines in different countries, most of them from Sweden. New technologies such as digitalization and automation together with new organizational forms engender changes in mining work, e.g., new types of work tasks, new competence demands, and a move from underground to high-tech control rooms aboveground. One main observation is that the changes challenge the old and recalcitrant blue-collar mining masculinity. On the one hand, the organizational resistance and "lagging" seemed to result in re-gendering and restoration of the male dominance. On the other hand, there were tendencies to adaptation in the workplace cultures, including new ways of forming mining masculinities, perhaps even undoing of gender. The main conclusion is that the most probable development lies somewhere in-between and by analyzing such complex processes of gender, technology, and change future research can get more knowledge of changes of gender constructions in working life.
\end{abstract}

Keywords Macho-masculinity $\cdot$ Mine work $\cdot$ Digitalisation

\section{Introduction}

The purpose of this article is to reflect on how the implementation of new technology, such as digitalization and automation, at mining workplaces, engender changes in work and organization, and how this, in turn, may challenge existing gendered norms and roles. In fact, a tendency of change in relation to gender has occurred at the mining workplaces over the past few years in Sweden. This can be seen in an increasing number of women working at mining sites and perhaps also indications of changes in the meanings of masculinities and femininities in mining work. These small yet observable changes can be attributed to general discourses and processes towards increased gender equality in the Swedish working life. However, when stepping into the mining workplaces, into

Jan Johansson

Jan.johansson@1tu.se

Lena Abrahamsson

lena.abrahamsson@1tu.se

$1 \quad$ Luleå University of Technology, SE 97187 Luleå, Sweden the everyday work, it becomes apparent that these changes are intertwined with other changes at the mining workplaces over recent time that are related to, for example, more automation, remote control technology and digitalization, improvement of the work environment, and safety. Step-by-step the mining industry moves towards a vision of automated and digitalized mines, and recently we can see an accelerated pace of change, which involves changes in the local mining work and new conditions for what constitutes work in a mine. This observation is one point of departure for the analyses in this article since such a transition is seldom easy and not without restoring responses and resistance in the workplace cultures. We are interested here in discussing how constructions of gender, and especially the mine worker form of masculinity, is involved in these complex processes of both resistance and change.

Large-scale industrial mining has long been a numeric male-dominated work context, in Sweden as well as globally, where the gender marking as masculine is seemingly stable, both when it comes to work identities and workplace cultures. Entering the mining environment is, or at least has been, like stepping into the very heart of a classic and dominant masculinity construction, the blue-collar masculinity. Although some may argue that the extreme form of this masculinity is 
practically outdated and no longer exists, it remains commonplace and continues to play an important role in gender constructions and gender segregation in work-life generally. It is a form of masculinity that serves as a relatively stable reference point depicting what a real man is, or should be: even for people, professions and masculinities that have quite different expressions, experiences, and norms. As Ely and Meyerson (2010) argue, a better understanding of how men "do" and "undo" gender in male-dominated organizations in relation to developments in the workplaces can facilitate a better understanding of the steadfastness that exists in the general gender pattern of working life - but also of its changes. Similar questions are raised by many practitioners as well, even though the questions are complex and there is no easy answer.

This article is predisposed so that we start with a description of the old but in some ways remaining mining masculinity and workplace culture, then presenting the current and coming technological and organizational changes in the mining context and the resistances that these changes meet. We conclude with a discussion on indications of changes in how mining masculinities are done or rather will or can be done. Empirical examples from our studies are used as illustrations that are integrated with discussions based on literature.

\section{Method}

This article is based on experiences from many years of study of large-scale industrial mines in different countries, most of them from Sweden but also Finland, Austria, Poland, Germany, Slovenia, and Australia. Based on these experiences, we have constructed a case that we call Mountain $L t d$. The frame of this case is a real underground iron ore mine in northern Sweden, with around 2500 employees in total, 1700 of them are miners. Our studies of this mine site began in 1986, with a critical analysis of the technical and organizational development (Johansson 1986). That was followed by two smaller but similar socio-technical analyses conducted in 2005 and in 2013-2014. It is the two last ones that are the main source for the empirical examples that are presented in this article, but to broaden and verify our analyses, we have supplemented and illustrated with parallel experiences from other mines.

Most methods we have used to collect data, in our studies, were qualitative: interviews, observations, field visits, interactive focus groups, and discourse analysis of historical and current Mountain Ltd. documents, such as annual reports, gender equality plans, health and safety statistics, as well as vision and strategy documents and research agendas. We have observed underground workplaces as well as work in production centers above ground. We have done four structural and longer site observations and numerous short field visits. We have interviewed both men and women, but mainly men, including miners, representatives of the mine labor union, mine engineers, middle managers (in production as well as in the technology departments), as well as senior managers. In total 25 semi-structural interviews, and in addition to that, we have had over 100 informal dialogues. We have also used interactive focus groups and workshops where we gathered mining workers and engineers, both women and men, during some work meetings to discuss gender equality in mining. Another activity is seminars with senior management and middle managers to discuss the same issues. These seminars acted as a complement to our general understanding of the mining context and were mostly done in an international mining context in three major EU projects on digitalization and intelligent mining systems during 2008-2020, where we studied the safety, ergonomic, and social aspects in connection with the development of new technology.

Since we have conducted several studies of mining companies over 30 years, we know the industry quite well. On the one hand, this has given us possibilities to avoid jumping on conclusions based on ignorance of the context or being bedazzled by the unique milieu in the mines. On the other hand, there is perhaps a risk that we know the context too well, and thereby risk losing in critical vigilance, but being based in a critical tradition, we have tried to keep our integrity and independence in relation to the companies as well as the context.

In our analyses, we have used the miners' resistance to new technology and organizational changes as a method to get hold of underlying norms, rules and practices, and their gendered aspects. For example, we do not study safety or resistance to safety per se, but only resistance to safety as an activity where masculinity can be done in relation to implementation of new technology and other changes in the organization. An inspiration for this method comes from Lysgaard's (1961) study of the "workers collective system," a system he argues to a high degree is formed on a culture of resistance, as well as Lindgren (1985) who applied a gendered lens to that theory arguing that the workers collective system is not gender-neutral, nor are work organizations. From this perspective, gender is seen as a complex system of social relations and practices in organizations that is interlinked with technology, work, etc. in constantly ongoing repeated social constructions and processes. Here, we are also drawing for example on Acker's (1992) notions on how organizations are inherently gendered as a result of for long having been created by and for men, and on Ely and Meyerson's (2000) discussions on social and organizational phenomena where gender inequality and conformity to conventional gender scripts can be produced, e.g., formal and informal organization of work, symbolic expressions, and everyday social interaction. However, similar to Ely and Meyerson's (2010) ideas of how male-dominated organizational cultures not only equip men to do gender but 
also to undo gender, we are interested in if and how the technical and organizational transitions of the workplaces can open up for new norms and forms of masculinities in the mining industry (see also Kelan 2018; Abrahamsson 2014; Deutsch 2007; Lorber 2000).

\section{A mine worker masculinity with roots in the old mining work}

As described above, our case company, Mountain Ltd., is a constructed case based on material from several studies of mining workplaces in several countries, but the main source is a mining company in the northern part of Sweden. Before we continue the discussion, we, therefore, want to say a few more words about the Swedish mining industry as a context. Employing some 8000 people in direct mining operations and around 8000 in subcontracting companies, the Swedish mining industry is a large capital-intensive export industry. It is comprised of a handful of large long-established companies and a few more recently establish smaller companies. Even if the mining industry is facing challenges today, due to global competition and demands for high sustainability (SIP-Strim 2019; Swedish Government Offices of Sweden 2013; Abrahamsson et al. 2009), mining is considered an important engine for both industrial and regional development.

This importance is also symbolic. Like other maledominated base-industries in rural regions, mining has no trouble attaining visibility and status in the surrounding societies as important, and large, something that affect the distribution of resources and opportunities to continue the benefit of men. Compared with other industrial jobs in Sweden, the level of pay cannot be described as anything other than high, and employment conditions are stable and good. Miner is not a high status profession, but in relation to other blue-collar professions in the mining regions, especially professions with an over-representation of women, such as elderly care and childcare, the miner has a stable high status. This can be seen as a basic aspect of the construction of the mine worker masculinity; yet, it is also part of gender construction in work life more generally, as well as regional identities, cultures, narratives, and discourses forming gender inequality (Abrahamsson et al. 2016; Ely and Meyerson 2000).

\section{Male-dominated mining work—with a few women}

At Mountain Ltd., just like in most other mining companies, the mining workplaces are male in a numeric, concrete, and obvious way: miners are almost all men. For many years, from around 1980 until 2005, the proportion of men in the Swedish mining industry remained reasonably stable: at $90 \%$ or more according to Statistics Sweden as well as Mountain Ltd.'s annual reports and gender equality plans. When it comes to actual miners, people that work underground, the proportion of men was even higher: around $95 \%$ or more. The proportion of miners that are women has increased slowly, in waves, from around 3\% in 1980 to around 5\% in 2005. However, over the past 10 years, the proportion of women has risen quite rapidly and reached more than $15 \%$ today. This coincided with a period of growth in the mining industry and the greater recruitment needs this engendered. Still, $15 \%$ is quite low compared to Swedish industry as a whole (that has $25-30 \%$ women) and in a wider perspective, the number of women within large-scale industrial mining in other countries, such as India (Lahiri-Dutt 2007, 2012) and Australia (Eveline and Booth 2002; Bryant and Jaworski 2011) are equally low, although it varies somewhat between countries, regions, and companies and from site-to-site. In her literature review, Macdonald (2017) presents figures of women's participation in extracting industries in developed countries and concludes that the ceiling for women in mining seems to hover around $20 \%$ and that women tend to remain at the lower level of the company hierarchy.

Despite the recently growing number of women, the Swedish mining industry is a rather stable male world. Yet viewed over a longer time perspective, it is quite clear that the gender numbers in the mining industry have not been stable. During the pre-industrial period, for example, many women, in a much larger proportion than today, worked in the Swedish mines. In some mines, women accounted for as much as half of the labor force. Blomberg (2006) describes how the Swedish mining industry underwent a process of masculinization during the industrialization period in the late 1800 s and early 1900s. The proportion of women working in Swedish mines decreased from 15 to $20 \%$ in the year 1850 to $1 \%$ in the year 1900. During this period of industrialization discussions about "true femininity" (i.e., the good caring mother and wife) were a general part of the public debate. The appearance of women, and their morality and sexuality, was criticized if they took part in heavy manual labor. The emerging opinion that mining work, especially underground work, rendered women incompetent as wives and mothers was becoming widespread. Additionally, in 1900, a new law introduced in Sweden prohibited women from working underground, ${ }^{1}$ although by the time this law was introduced, almost all women had already left the mines.

In 1900, when Mountain Ltd. began harvesting the iron ore in the north of Sweden, mining work had the purely male character that it has today. Nonetheless, there have always been women hard at work in the mine, with hand picking and sorting ore for example. However, as the work has

\footnotetext{
${ }^{1}$ The Swedish law from 1900 was not removed until 1978. However, mining companies could ask for exemptions and many did so. In the 1960s, Mountain Ltd. recruited several women to work both above- and underground. The first time a woman was allowed to work as an underground truck driver was in 1963.
} 
become mechanized, the number of women employed at the mine has decreased: just as it has in other industries and other countries (Lahiri-Dutt 2007, 2012). As Blomberg (2006) and Lahiri-Dutt and Macintyre (2006) note, the old mining narratives of both trade unions and the mining industry has made women invisible, positioned as different and their mining work devalued. This functioned as part of the constructions of the mine worker identity and masculinity and probably still does (Mayes and Pini 2014; Norberg and Fältholm 2018).

Eveline and Booth (2002) give a modern example of the disappearance of women from mining work; in an Australian mine, the proportion of women decreased from $28 \%$ in the year 1984 to merely $4 \%$ in the year 2000. Eveline and Booth note that women had to deal with subtle sexism as well as open hostility and sexual harassment; there was open opposition to practical arrangements, such as women's toilets in work areas and the provision of small-sized safety gloves, as well as ideological opposition to the recruitment and advancement of women. Some practical jokes generated physical dangers for women. One example of this is that some of the men dumped ore in unsafe places, placing the women who were operating loaders and other machinery at risk. More common was the failure of men to inform women workmates about risks and other events in the production process. Similar depressing stories of opposition and sex discrimination against women miners are well documented in research; see for example, Eveline (1989 and 2001), Yount (1991), Lahiri-Dutt (2007, 2011, 2012 and 2013), and Tallichet (2006). The situation today is generally better. Despite this, some of the women in our Mountain Ltd material (from both 2005 and 20132014) spoke about the wide use of harsh heterosexual jargon and how they had been subjected to comments about them, as women, being in the wrong place, and that women do not belong in the mine, that the work is too dangerous, too unhealthy, too demanding, or too technical for women. Some of the women explained that this talk was most coarse when it took place over the internal communication radio. Although the comments and the sexist jargon were directed in part to the few women in the workplace, it is our opinion that it was, probably, also directed at the majority; as messages to the men how to behave, and it, therefore, became a part in the constructions of the mine worker identity and the associated masculinity.

Related to this is the global historical myth that the presence of women in mines leads to accidents and deaths, and therefore women should not perform mining work (Mercier and Gier 2006; Tallichet 2000). When visiting mine museums, these stories, perhaps told with playful seriousness, keep this myth alive. At the Mountain Ltd., there is an old tale about the rock being a whimsical woman who does not accept the competition of other women, and this jealousy causes falls and accidents in the mine (Andersson 2012). Today, people that work at the mine view this tale as a joke, explaining that this does not really matter anymore. Yet, a few of the women that work in the mine argue that the tale is still is used to scare women away from working underground.

It was also quite easy at Mountain Ltd. to recognize the minority effects coined by Kanter (1977) and the individual strategies that women use to be able to cope with these effects. Several of the women miners, for example, explained to us that they mostly just used to try to fit in as one of the boys, being excellent miners, tough and able to answer in the same hash style, or just to put a blind eye to the men's sexist behavior. Mayes and Pini (2010) argue that this way of claiming gender neutrality departs very little from the hegemonic versions of the masculine norms in mining while leaving this norm intact and unmarked. However, we would like to add that in our more recent workshops, we observed that many of the women miners quite often also openly used feminist arguments for gender equality in their struggle against both their male workmates as well as managers. As we later on will discuss, we chose to see this as indications of the last decade's quite gender equality friendly discourse in Swedish industry.

\section{Masculinity and a homosocial workplace culture}

The numerical male dominance as well as the problems, hinders, and obstacles women in the mining sector have been and are still facing are not without significance for the constructions of the mine worker masculinities. Mining and masculinity have been described and analyzed by many gender researchers - some of which forms the base of the analyses in this article (cf. Abrahamsson and Somerville 2007; Andersson 2012; Blomberg 2006; Eveline 2001; Eveline and Booth 2002; Lahiri-Dutt 2007, 2012; Laplonge 2014a, 2017; Mayes and Pini 2010, 2014; Somerville and Abrahamsson 2003). In those studies, consistent descriptions of, for example, how mining work has been long determined as requiring qualities and qualifications that are viewed traditionally as being male, such as being a physically strong, tough, loyal, brave risk-taker, and problem-solver, are documented. Even when technology has contributed to improving the work environment, the aura of very dangerous, heavy, and dirty work has continued to surround mining. This is also the case at the Mountain Ltd. mine, and we would like to include the old type of hard "manual" underground work close to the ore face and practice-based knowledge of the rock, and its extraction, to this picture. The current local hegemonic mine worker masculinity is still to a great extent constructed around the mystery of the rock and old tales about mining: as one of the interviewed men stated: "As a miner, you must learn how to cope with and appreciate the secrets of the mine. The environment in the mine is unique and the mine itself is mysterious, it's important to keep it that way!"

The interwoven constructions of mine work and masculinity make it especially difficult for the men to be associated 
with competences, attitudes, or behaviors that have a female gender code, as is also the case in other male-dominated workplaces (Eveline 2001; Gherardi and Nicolini 2000; Ely and Meyerson 2008, 2010; Kelan 2018). But as Connell (1995) argues, the constitution of masculinity is not only a negative mirror of femininity, it also acts to provide barriers against other men, lower-ranked masculinities and, especially, unmanliness. In our Mountain Ltd material, the fear of being seen as less masculine is visible in the sexist jargon and the tendency to chastise men that are not strong enough or are unwilling to take risks. An example of this is the mine worker that wanted to stop a job for safety reasons but was sneered at by workmates; "Are you chicken or what?" Related to this is, as we will be describing later, the positioning of the remote control work from aboveground in the lower part of the masculinity scale compared to the real and more masculine underground mine work.

From this perspective, we argue that it is no wonder that overexplicit expressions of a mixture of traditional blue-collar masculinity (cf. Collinson 1992; Whitehead 2002; Willis 1977) and rural masculinity (Stenbacka 2011) exists at Mountain Ltd. and forms a special type of mine worker masculinity, a "macho-masculinity" (Somerville and Abrahamsson 2003; Abrahamsson and Somerville 2007; Laplonge 2014a). Although this type of masculinity is pictured by some people, at least formally, as reactionary and in many ways problematic, it enjoys certain support in the local community close to the mine. The men appear to experience it as an enjoyable and undemanding base for social interaction and belonging, a source of pride and a focus of loyalty to workmates, the working class, and the mine. This may be a way of dealing with feelings of stereotyping, subordination, and inferiority (cf. Willis 1977; Collinson 1992).

Another explanation for the long survival of this kind of almost obsolete masculinity expression is that in mining, as in other male-dominated industrial organizations, workplace cultures are often based on brotherhood, male bonding, malesocialization and identification, as well as the exclusion of others: mainly women; office staff; management; and people from other parts of Sweden, other countries, and subcontracting companies. This controls and reinforces the similarities between workers. This can be understood also without a gender perspective and has been described by Lysgaard (1961) as a "workers collective system," a normative system based on class consciousness and a culture of resistance by people in order to gain informal control over the work situation, a system that functions as a buffer or protector against the demands of production and hard work. Such processes can also be discussed in terms of organizational disobedience and misbehavior (Collinson 1988; Ackroyd and Crowdy 1990; Collinson and Ackroyd 2005; Karlsson 2011; Linstead et al. 2014). In our Mountain Ltd. material, there is some evidence of sabotage of materials and machinery (especially the automated machines) and not following safety rules. But mostly, the disobedience was about keeping down the pace of work, cheating with working hours, having secret routines and hiding places, or taking the power to decide who is and who is not going to be recruited to the team. Some of this is perceived as half-sanctioned by the management. Although the workers' collective system protects the employees from the demands of production and can also form a base for positive workplace learning and identity processes, the workers' collective system itself is inexorable (Fältholm 1998). As the strength of the workers' collective system is manifested by conformity to informal rules and norms of likeness, deviations from those norms are punished accordingly.

When women enter a male-dominated workplace, as Lindgren (1985) argues, the abovementioned norms of likeness, as well as the common worker identity and the whole workers collective system, are being challenged. This instigates the activation of a gender-order system founded on and sustained by the separation of, and differences between, the genders. In the case of mining, the workers' collective system is sustained by the reproduction of hegemonic macho-masculinity, keeping the number of women as low as possible and, if the number of women increases, forming clear boundaries between men's work and women's work.

However, behind the overexplicit discourse of macho-masculinity, there is a wide spectrum of individual expressions. The term hegemonic masculinity (Connell 1995) is commonly used to illuminate the fact that there are many parallel and interacting versions of masculinity and that one form of masculinity will generally have dominance over other expressions of masculinity. In the Mountain Ltd. mine, we identified similar patterns, albeit of a smaller scale. Andersson (2012) observed three main types of male mine workers. The first group was a small group of outspoken almost aggressive men who oppose anything new, especially increasing the number of women mine workers and gender equality. This group can be seen as personifying the many mining hero stories about some macho men, around which the local hegemonic masculinity was in all probability constructed. The second and also the largest group was comprised of more silent men, who took no position on these issues. They did not live or act fully following the ideals and norms associated with macho-masculinity. They were at least taking a distanced position towards the idea of the need and presence of macho miners today. Several of them were asserting that "We are no longer macho-men in the mine!" But at the same time, many of these men often defended, even glorified and promoted the local hegemonic macho-masculinity. They loved telling stories about mining life and work in the past, romanticizing the hard life back in the good old days. It was in this way that the old story of mine work was restored and conserved. All miners, at least the men, shared the same image of what a real miner was, or is; a man, working underground 
with manual, dangerous, and mysterious work tasks. By this, they chose to be in the neighborhood, as a follower or liker, of macho-masculinity. Connell (1995) refers to them as complicit masculinities and means that by taking this position people get some of the respect, authority, power, material, and economic benefits that are associated with the dominant form of masculinity, in this case, the local form of mining machomasculinity, but not with the sometimes difficult exposure of being in the frontline. The third group, Andersson (2012), identified was a small group of men that saw both the new technology and gender equality as important for the survival of Mountain Ltd. and the mining industry as a whole. They emphasized the similarities between women and men and had nothing against to share the mine with women. This group of men can be seen as representing new forms of masculinities that are allowed in the mine (Fältholm and Abrahamsson 2015) as well as examples of men undoing gender at work (Kelan 2018; Ely and Meyerson 2010).

\section{Masculine mining work in a changing context}

The descriptions above depict a mine worker identity that is deeply rooted in the mine work of the past, the male homosocial workplace culture and the mine worker macho-masculinity. It is also rooted in a stable, high status, and capitalintensive work context. However, as mentioned in the introduction, the mining industry is also an industry in transition. Mountain Ltd. has continuously invested in the development of new technology intending to increase capacity, quality, and safety of its mining operations. While there has always been a machine between the miner and the rock face, that machine has become larger over time and is today, with the introduction of new technology, also becoming more abstract where the interaction with the machine takes place indirectly through various control systems (Johansson 1986; Abrahamsson and Johansson 2006).

\section{The physical work environment is improved}

Until the 1980s, the reality at Mountain Ltd., more or less, was that mining was hard, physical, and dangerous manual work performed under difficult conditions (Johansson 1986). During the 1980s, work conditions in the mine gradually changed; the first driverless trains were introduced, and many work tasks were now being performed in underground control rooms or driver cabs. During the 1990s, the level of automation increased, and an increasing number of work tasks became remote-controlled, even if still from underground control rooms. A part of this development was the clear improvement of the physical work environment down inside the mine. Problems with heavy lifting, noise, and gases have been, almost, eradicated, and high-tech developments have reduced the risk of accidents, injuries, and occupational diseases. In addition, systematic methods for the improvements in the work environment, work organization, and safety culture have had positive effects.

\section{Mining becomes an office work}

During the past few decades, Mountain Ltd. has undergone a gradual transformation from mechanical underground work to remote-controlled work (Abrahamsson and Johansson 2006). One important step occurred in 2004 when part of the mine work moved into a pleasant modern remote operation center above ground, to the seventh floor of the office building with a panoramic view over the town and the surrounding mountain area. This move to a kind of office environment involved major changes in the working context for some miners, from a blue-collar context underground into a kind of white-collar environment aboveground. For some of those miners, real contact with the actual rock became rather rare. In 2013, Mountain Ltd. once again modernized the operation center and moved it to a new building of its own. Today, large computer screens dominate the workplace.

\section{The digitalized technology is becoming more and more dominant}

The recent emergence of powerful digitalized and autonomous technologies has accelerated the pace of change, for example, mobile robots, drones, and intelligent systems that sense and learn about their environment. The integrated and connected mine through technologies as $5 G$ and the internet of things (sometimes called Industry 4.0, intelligent digitalized systems where computers, machines, sensors, and humans are connected and communicate with each other) is a vision being discussed ever more frequently by both researchers and mining companies, so also at Mountain Ltd. In their plans for the future, they call it "Mountain 4.0."

This techno-optimistic vision of the future mine workplace has great hope in the possibility of creating better safety but also attractive, stimulating, and self-developing work tasks for the individual through a combination of new technologies and new forms of collaboration (Kagerman et al. 2013; Lasi et al. 2014). There is also, of course, some awareness of the criticism of this development, in terms of jobs disappearance, job insecurity because of crowdsourcing, more surveillance of individuals, and de-qualifications where future miners will be enclosed in a technical system they cannot control, but this criticism is not as intense as the approving enthusiasm.

\section{From manual to technical qualifications}

A consequence of technological and organizational development is that there is an emergent, and in many aspects already 
evident, transformation in what qualifications and knowledge is applicable in the mining workplace: from the old, obsolete bodily and tacit knowledge and skills, the pit sense, into something new (Somerville 2005; Somerville and Lloyd 2006). Using Kern and Schumann's (1974) concepts, this can be described as a transformation from craftsman-like qualifications in the form of autonomy, manual skills, and sensitivity to the material (rock-sense) into more technical qualifications based on abstract knowledge necessary to control the new advanced machines and equipment. In Mountain Ltd., we see higher demands for the miner to have a comprehensive understanding of the whole production flow and be able to work independently while at the same time being part of a team with common goals. We can also see that what was previously the tacit knowledge of the miner is now increasingly becoming formal knowledge, which can be stored in a computer or smartphone and be automated. This shift involves contradictory movements of up-qualification, which involves rapidly changing skill demands, more theoretical, comprehensive, and communicative tasks, as well as "de-qualification," which involves the fragmentation of individual craft knowledge and routinization of work tasks. There is also a form of re-qualification. The new skills and knowledge are in some respects more abstract and theoretical than was previously the case, but in other respects, they are still bodily and tacit: only in a different way with less force and increased precision, whether a question of up-qualification, de-qualification, or re-qualification, the transformation of knowledge has had an effect on the workplace culture and the miner identities of the past.

\section{A new type of miners}

It is clear that in the future Mountain Ltd. and other mining companies will recruit people and competencies that differ radically to those of the past. Even if the development of technology is the dominant narrative at Mountain Ltd., there is also a growing interest in, and implementation of, organizational concepts inspired by Lean production: in this case, in Lean Mining (Lööw 2015). There is also an emerging specified objective to create attractive and sustainable workplaces, and statements of a need to transform existing organizations are increasing in intensity (e.g., Johansson et al. 2010; Abrahamsson et al. 2014; SIP-Strim 2019). This planned transformation includes not only new skills but also demands of higher quality and safety, as well as an expressed need for a change in attitudes towards safety culture, diversity, gender equality, environmental concern, and social sustainability (cf. Laplonge 2017). Mountain Ltd. is, for example, right now mapping their qualification needs, not only in relation to the new digitalized technology but also to other aspects of the new types of work that will be needed in the future, such as creativity, responsibility, respect, and long-term perspectives.

\section{More women underground and higher demands on gender equality}

Another part of the changes within Mountain Ltd. is the growing number of women that do mine work (an increase from $5 \%$ in 2005 to almost $15 \%$ in 2015) and women that are production managers and top managers, as well as changed policies and informal norms for the organizational culture towards more gender equality. As mentioned in the introduction this can be unintended side effects from the new technology in combination with incremental changes due to general social trends in Sweden, such as gender equality policies, ${ }^{2}$ increased number of women on the labor market and a gender equality friendly societal discourse, as well as some endurance in the gender equality and diversity interventions from the company's side. Even if the gender equality interventions have not been any major part of the company's organizational strategies, Mountain Ltd. has been engaged in promoting gender equality since the 1960s. Examples of this include the retraining of women and recruitment campaigns targeting women to get more women as miners, the analysis of the work environment to identify positions that it is possible for women to hold, an annual pay review to see if there is a gender gap, and the removing of pictures showing half-naked women from locker rooms. Furthermore, women's networks have been established, gender-awareness training given: recruitment campaigns for women executives and technology experts have been run and an educational program focusing on mining with $50 \%$ being young women was introduced at upper secondary school level in the local social context. As part of its marketing strategy, Mountain Ltd. chose to depict women as being vital for modern mining. We also heard from managers, engineers, and miners (both men and women) informal claims that women drive the trucks in a safer way than men do, and that women miners will almost automatic and naturally alter the macho-culture of mining workplaces. An example of the more recent gender equality approaches involves officially presenting the company as a modern, responsible, and progressive high-tech company where gender equality and diversity are important aspects of its work with social sustainability, as well as a social license to mine.

In addition, during the past 10 years, Mountain Ltd. has been involved in two research projects, attempted to integrate theoretical gender perspectives into the company's work with the safety culture and in discussions about how the machomasculinity and workplace culture might be changed (Andersson 2012; Ringblom 2019). Similar approaches (cf. Ely and Meyerson 2010; Meyerson and Kolb 2000) can be found elsewhere in the world, for example, in Australia

\footnotetext{
${ }^{2}$ For example, long and paid parental leave for both the mother and the father, a good childcare system, laws regulating employers to do annual pay reviews and gender equality plans.
} 
(Abrahamsson and Somerville 2007; Somerville and Abrahamsson 2003; Laplonge 2011). These researchers argue that there is a need to address the men, the majority, when discussing gender equality, workplace culture, organizational change, and safety in the mining industry; however, at Mountain Ltd., this has not yet been implemented.

\section{New technology meets a reluctant context}

As described above, there have been several changes in the mining context, while some are already evident, others are on their way. However, the process of change is never straightforward and is often met by initial resistance, restoring responses and backlashes connected to power, control, work identities, and discourses. This is also the case at the Mountain Ltd. mine, where change is met by a reluctant context, a workplace culture that acts to produce restoring responses and resistance to change. Below, we present some examples of how the miners struggle against the transformation of mining work and new forms of managerial controland how they in many ways at the same time are doing gender mostly in a traditional and stereotypic way (cf. Ely and Meyerson 2000, 2010; Kelan 2018; Abrahamsson 2000, 2014; Ashcraft 2005).

\section{Resistance to new technology}

One such example of resistance, from the 1980s, when remote control was first introduced at Mountain Ltd., was the desire expressed by employees for large joysticks that resembled the feeling of driving a loading machine; today, this is not an issue at all, everyone works with keyboards and finger joysticks based on visual perception. Another example, from 2005, when the first front-loaders (all men) moved from an underground location to steer and control the loading machines remotely from the remote operations center on the seventh floor of the office building, is that employees continued to use work-wear and changed clothes in the locker room after every shift despite the fact that they were just as clean as when they arrived. This stopped after a year or so and they began to wear jeans and t-shirts or similar clothing, just as others that work in an office do. It is reasonable to explain this as a desire to be "real" miners, to be the same as those that work in a dirty and more dangerous environment underground. Even if all of them were men they had probably difficulties to maintain the image of macho mine work in a control room. This can also be explained as an effect of remote control: that the work tasks seem much simpler after they have been moved out of their context (e.g., the physical place underground where the loading or drilling machines are situated). When the work tasks do not need to be conducted in a mystic, difficult, and tough work environment, the aura of job secrets and tacit knowledge or craftsman-like qualifications disappears. This means that it can be difficult to retain the feeling that mine work is unique and the connection to the history of the mine.

The introduction of the remote control at Mountain Ltd., and especially the move up to the seventh floor of the office building in 2005 , engendered the division of employees into groups of us and them. Employees working underground, especially those working with more manual tasks, perceived themselves as real miners in comparison to people working through remote control. They were perceived as weaker and womanish. The people working underground called, half-jokingly, the remote operations center "The Seven Heaven," referring not only to its position on the seventh floor in the office building but also to the contrast between this nice, comfortable workplace, and the traditional mining environment. They also gave remote-control workers' nicknames such as "the velour workers," meaning that they are of a soft type of men, almost feminine, and not real macho miners.

Part of the resistance is focused on the new digital technology itself. In our study from 2005 miners, mining engineers, and middle managers (all males) displayed a general hesitant attitude towards remote control and automation. They did not really want to identify the mine with the new technology, favoring older technology connected to traditional underground mine work down at the ore face, technology with a stable gender marking as male. One miner tried to explain that what he was doing was real mining, "You get pissed off when all you see in the media are photos of girls in front of computer screens. In my workplace underground, we still use the same heavy tools as in the 1950s, but no one describes our job!" Furthermore, our follow-up study in 2013-2014 produced several statements that automation, driverless vehicles, and zero-entry zones is "an unrealistic vision," and that this is not an efficient way for the mine to function. There were practical problems with the implementation of the new technology in some areas, one miner explained why, with a dose of self-irony: "Automated loading is not working because the loading is an old craft. Here automation is seen as the ruthless exploitation, it has always been so."

In 2014, one mining engineer, actually tired of these negative attitudes, said in a workshop: "It is not true that manual work is more efficient, automatic machines do work better. It is a question of will. It is the humans who deliberately "destroy" the automated machines." The incidents of reported direct "sabotage" of the automation can be interpreted as an extreme form of resistance within the workers' collective system of new technology. Today, the major issue discussed in the technology departments of mining companies is the resistance of employees and labor unions to the wearable sensors and other IT tools that facilitate the positioning of people. This resistance is understandable when considering the issue of personal integrity, but also because it encroaches on the areas 
of power and the informal control that the workers' collective system, and through that macho-masculinity, has.

A more direct connection between gender and hesitant attitudes towards the new technology can be found in the observations by Olofsson (2010) of how the new automation technologies and robot machines introduced at the workplace of a mining subcontractor close to the Mountain Ltd. mine site underwent a process of feminization and became women's work. This can appear to be somewhat paradoxical because technology, especially new technology, such as digitalization, robotization, computerizing, and other high-tech areas of development, are assigned to men and largely associated with men and general constructions of masculinity (see for example Wajcman 1991; Mellström 2004). It is, however, easier to understand when related to the importance of old mining work for the construction of mine worker masculinity. A similar example is the observation of Eveline and Booth (2002) that the equipment on which women excelled, particularly the huge computerized trucks and dozers, were marked as female machines. As a result, some men refused training in the use of these machines, because they believe that such training would diminish their sense of masculinity, not to mention their fear of being outperformed by a woman. The refusal of men to do female or womanish work, the openly negative attitudes towards women in the workplace, and the informal desire for macho-masculinization within the workplace culture, can be attributed to people, women as well as men, defending existing local gender orders, and local masculinity. A pattern similar to this has been observed, also by Abrahamsson (2000, 2014), in the pulp and paper industry.

The gender marking of the new technology as feminine was not so clear at Mountain Ltd., but in our observations from 2013 to 2014, we saw how new technology was repeatedly perceived as an enabler for the employment of more women at the mine in the future, especially if work tasks are moved above ground and controlled remotely. Related to this, we saw indications of an emerging gender segregation within the workplaces at the Mountain Ltd. mine. The physically strong and tough male body was still informally considered, among the male miners, a prerequisite for mining work, the real mining work. Previously, there was a clear "gender boundary" at the gate of the mine site's production areas, since almost all the work there was done by men and had a stable gender marking as male. This boundary appears to be shifting from the gate into the production areas; today, it stands between work that utilizes traditional technology that is marked as work primarily for men and work that utilizes new technology, related to remote control and automation, that is marked as work that can be performed by men or women (Ringblom and Abrahamsson 2017). However, this is probably a temporary condition. The new technology is gradually gaining ground in all parts of the mine, and it is likely that in the future mine worker masculinity will change to reflect this.

\section{Resistance to safety}

Another example of resistance is the rather nonchalant attitudes towards safety, such as the tendency to chastise men who attempt to follow safety praxis. Examples of working without a safety device over an open shaft, and employees that do not react to the alarm on the gas indicator when it warns of high levels of $\mathrm{CO}$, have been observed at the Mountain Ltd. mine. Yet the situation at the mine was not as bad as it is in Australian coal mines where Abrahamsson and Somerville (2007) observed an all-male workplace culture so strongly founded on risk-taking, competitiveness, and "macho-masculinity" that it acted to suppress the many years of safety training and education that the company has provided employees with. It was nonetheless bad enough at Mountain Ltd. Accidents did happen. Andersson (2012) notes that men at the mine often took risks not only because of the need to prove themselves tough and male but also because of solidarity with other men, a form of moral obligation between miners. In an underground coal mine in Canada Wicks (2002) observed similar connections between masculine institutionalized identities and organizational dysfunction, which created a situation in which a fatal accident occurred. Laplonge (2014b) describes other examples of how masculinity is very much involved in how risk-taking and safety are understood at mining workplaces.

The issue of resistance to safety also has more discursive aspects. At Mountain Ltd., there was a tendency for miners to exaggerate the old technology, the difficult work environment, and the dangers and the risks of the work, to greatly emphasize the mine as a dangerous place. The mining labor union also drew attention to the hazards of mining, both on a general level in mass media and internally in negotiations with the employer, as an argument for more safety, better working conditions, and higher wages. This strategy is hardly surprising given that a large part of the miners' high income is legitimized on the grounds of the special conditions of underground work. This is an indication that there is a complex set of forces that simultaneous strive to maintain these special conditions. If safety is too good, and mining too much like ordinary industrial work, it will probably be difficult to legitimately argue for a high wage level and the feelings among the male miners of the risk of being substituted by anybodyeven women - grows.

The discourse of dangerous mine work also functions to protect the status of the work and retain the old identity of the "real miner," including, of course, the possibility of appearing as heroes and real men. The conservative aspects of the workers' collective system can also help explain this: the combination of difficult working conditions and the old manual work is the basis for the existence of the workers' collective system (Lysgaard 1961). This means that the implementation of new technology and/or new forms of organization are often 
thwarted by the workers, at least initially, not because there really is something wrong with the new, but as a way to preserve the old type of mine work and, we would argue, by that also the old mining masculinity.

At the mine studied by Eveline and Booth (2002), superintendents and subordinates, all men, used derogatory nicknames, such as "The Fairyland," for the on-site training center, implying that not only safety but also learning and training were soft, not manly enough. We can, therefore, expect that the growing expectation that the individual must take responsibility for safety, continuous improvement, development of workplace culture, learning new skills, and competences will be threatening the workers' collective system as well as local masculinity also at Mountain Ltd.

\section{Resistance to gender equality}

Some resistances were connected to the growing number of women miners. In our study 2005, one male miner explained: "There are enough women in the mine now," even though, at that time, only $4 \%$ of the people that worked underground were women. As described earlier, there were some concrete resistances towards women miners, but this can also be seen as results of the image of women miners becoming a symbol of the modernized mining work. The more different kinds of people that work in the mine, then the harder it becomes to maintain the mine worker masculinity, the homosocial workplace culture, the feeling of uniqueness, and the links to the stories of old mine work.

Most of the gender equality approaches at Mountain Ltd. have focused on "fixing" the minority, the women, seeing women as both the problem and the solution (Abrahamsson et al. 2014; Ringblom 2019) and creating equal opportunities, similar to the approaches of networks such as Women in Mining. Even though these approaches have to some degree been based on gender theories they tend to have been mostly policy-based and not really questioned or changed existing gendered practices and cultures within the company (Ely and Meyerson 2000). But despite this, even the policy change was met with resistance and negative attitudes, such as "Now gender equality has gone too far" and "You cannot sit beside a woman on the bus without being accused of sexual harassment."

In our workshop material from 2013 to 2014, we saw that the focus of the gender equality interventions of Mountain Ltd. was a "business case" for gender equality (Johansson and Ringblom 2017; Macdonald 2017; Laplonge 2017). Mayes and Pini $(2010,2014)$ note similar development in the Australian mining industry and argue that a dominant storyline in media as well as in the mining industry's own documents is one of gender change, but their analysis shows continued positioning of hegemonic masculinity as central but invisible and unremarked and that this has resulted in a view of gender equality approaches as unnecessary and unfair (Johansson et al. 2017). Similarly, as Laplonge (2016) argues, the common informal claims of women being (naturally) safer drivers or are better than men in some other special aspects do not challenge gender stereotypes and the still quite common essentialist and sociobiological notions of what women and men should be.

\section{A workplace culture lagging behind}

In our observations of resistance to change described above, it is quite easy to find connections and similarities to many of the examples, compiled by Kelan (2018), of how men are doing gender at work, following gender-normative expectations, and by that producing gender differences and gender inequality (cf. Ely and Meyerson 2000, 2010; Deutsch 2007). In our Mountain Ltd. material, the expressions of the old mining masculinity seemed to not only engender informal problems for the implementation of new technologies, new work roles and organizational forms, and safety and environmental awareness. It also seemed to erect barriers for a diversity of lifestyles for men, hindering men to enact gender in nonnormative ways, and it functioned as gatekeeper excluding women and hindering gender equality interventions.

One explanation of the different forms of resistance observed in the mining context is that the socialization, learning, and identity reconstruction of mine workers takes place, primarily, within the old workplace culture and its associated gendered organizational formal policies, informal practices, narratives, and informal everyday social interactions (Ely and Meyerson 2000; Acker 1992). As also Laplonge (2017) discusses, for the male mine worker, it seems vital to support the existing mining culture and practices. Their status as real men relies on the status quo of mining. If they take any form of more progressive positions, they risk losing their masculine status. This applies not only to mining and other similar industrial male-dominated workplaces. Abrahamsson (2000, 2014) shows how discourses and constructions of gender, femininities, and masculinities; at workplaces are often conservative and can engender distress and restoration responses during organizational change and the implementation of new technology. In a similar way, Ashcraft (2005) discusses how seemingly privileged professional men, such as commercial airline pilots, perceive and respond to gendered identity threats that come from organizational changes. Through of complex forms of resistance, they can maintain a manly profession.

It appears as though the workplace culture and mine worker identity are, or at least have been, lagging behind, in a similar way that long-distance travelers can be jet-lagged and experience being in the wrong time zone. With lagging behind, we mean that the symbols of mine work, the images and narratives and the mine worker identity and culture, have 
for a long time stayed in an old-fashioned mode in many aspects, at least in relation to what the new technology such as digitalization and automation imply. The symbolic and discursive connections between mine work and masculinity, often the specific macho-form of masculinity, probably make the lagging resilient and extensive.

\section{New mining masculinities or not?}

But just like after a period of jet lagging, one eventually reaches the same time zone. Perhaps this phenomenon is what we can see in our other main observation that adaptions and changes are happening. It is not only a question of defending and restoring the old mining culture, the male mine worker identity and macho-masculinity. At least new things are important today, as compared to yesterday. The management of Mountain Ltd. is expressing a need to move on from the old blue-collar worker roles and the traditional male workers' collective system and support the mine workers to take a position in a high-tech, or even white-collar worker, environment. One conclusion that can be drawn from this is that new ways of defining mining work, qualifications, competences, and of constructing identities are emerging. This also includes gender. The old type of macho-behavior and the male mine workers' collective system is progressively becoming obsolete and people that work in mines are simply adapting to changes. There are already indications of new ways of doing or perhaps even of undoing gender resulting in new expressions of mining masculinities, and femininities, that share space with the old and, perhaps, vanishing machomasculinity (Ely and Meyerson 2010; Somerville and Abrahamsson 2003; Abrahamsson and Somerville 2007). There is, as earlier described, a growing number of women employed at Mountain Ltd., as miners and as managers. Moreover, there is a changing workplace climate that, according to the interviewed workers and managers (both women and men), includes more positive and inclusive attitudes and potential nonnormative gender practices and reduction of gender differences, that according to Kelan (2018) can be part of undoing gender. Another example is the fact that in 2016, for the first time in history, a woman became the president of the local mining labor union. In recent years, the town has witnessed developments such as a Pride festival and in 2014, as a tribute for the Pride movement: the local men's ice-hockey team chose to play in rainbow colors and to provide training in LGBT (lesbian, gay, bisexual, transgender/ transsexual) issues for the team.

However, the image that emerges is of a multifaceted context where mining work of the future is under negotiation, resulting in conflicting emotions and behaviors. Andersson and Abrahamsson (2007) characterize these conflicting emotions and behaviors among the employees, primarily men, at the Mountain Ltd. mine in three ways. One is to glorify the mystery and history of mining and be negative towards new technology, while at the same time being proud of and reliant on technological progression and modern mine work. Another way is to encourage nonchalant attitudes towards safety, while at the same time emphasizing the concept of a safe mine. Yet, another way is to preserve macho-masculinity by resisting the specific gender equality approaches at the workplace while simultaneous pursue gender equality generally in society. This can, on one hand, be seen as discursive tactics where the employees resist the changes and restore control and status of the profession (Ashcraft 2005; Johansson et al. 2017). On the other hand, despite, or perhaps because of, the dual and contradictory nature of these emotions and behaviors the mining context can be seen as open to change and forming cracks in the traditional male workers' collective system, opening up for undoing gender and changes where something new can emerge and grow.

\section{Concluding reflections}

In this article, we have used Swedish underground mining work as an illustration of both the stability of masculinity and its propensity for change. Here, we confront a reluctant context were the local hegemonic masculinity, a kind of macho-masculinity, is rooted in the old type of mining work and mining identity. At the same time the sector is adapting to digitalization, which certainly will engender changes in mining work, some already in place. Our main observation is that the workplace culture, and the narratives on what a real mine work and a real mine worker is, are gradually changing, in content and character, to suit the requirements set by the digitalized technology, the new qualification demands and new organizational forms. And also that in these processes, changes of masculinity and the ways how men are doing, and perhaps undoing, gender are very much involved. We do not yet know how and in what directions, but we can sketch two scenarios as suggestions for future research.

The first scenario is probably the most likely and it contains processes of re-gendering that slowly are changing the mine worker masculinity to suit the new situation. This can seemingly look like processes where the men are undoing gender, described by Kelan (2018) and Ely and Meyerson (2010), but mining work and its technology continues to be just as manly as before, only digitalized and linked to a different type of masculinities and different ways of doing gender, with some reduction of the most negative elements of traditional mine workers masculinity. Ashcraft (2005) would perhaps describe this as the effects of tailored resistance or even resistance through apparent consent. The numerical and the cultural male dominance in both mining and digitalization can, therefore, be sustained. The increased but still rather small number of women in mining does not create 
gender-mixed workplaces; instead, the gender segregation is strengthened in the new types of mining workplaces. In this scenario, the mining industry will probably continue lagging behind in some respects, especially when it comes to gender equality.

The second scenario is that mining work is purged of masculinity thanks to the demands of new digitalized technology and a new kind of societal context that is incompatible with the traditional mine workers' masculinity. As Ely and Meyerson (2010) argue, the men will orient themselves towards the new work goals and the organization loosens the grip of how men enact maleness at work. The link between mine work and masculinity is removed or at least reduced. This opens up for a kind of real degendering or undoing of gender and creating mine work that can be and also is performed by both men and women and therefore less gendered. An industry or an occupation in which gender does not matter is probably a utopia, but an interesting thought that contributes to unmasking existing gender patterns of today and identifies pathways for new forms of gender patterns in working life. This second scenario, the path to utopia, is very much techno-optimistic, perhaps too much, but it should not be routinely rejected just because of lack of knowledge of its inherent potentials. And as Kelan (2018) points out, we have quite a good idea of how men at work contribute to gender inequality but know less about how they contribute to gender equality.

We conclude that the most probable development lies somewhere in-between these scenarios. By analyzing processes, discourses, and structures of both the scenarios and the whole scale between them, future research can get a better understanding of what undoing gender by men at work might look like. These are questions that many practitioners raise as well. The questions are complex and there is no easy answer. More knowledge is needed on how processes of gender, technology, and change are interlinked in different ways and affect, in positive or negative ways, opportunities for development towards a sustainable and gender-equal working life.

Acknowledgements Open access funding provided by Lulea University of Technology.

Open Access This article is licensed under a Creative Commons Attribution 4.0 International License, which permits use, sharing, adaptation, distribution and reproduction in any medium or format, as long as you give appropriate credit to the original author(s) and the source, provide a link to the Creative Commons licence, and indicate if changes were made. The images or other third party material in this article are included in the article's Creative Commons licence, unless indicated otherwise in a credit line to the material. If material is not included in the article's Creative Commons licence and your intended use is not permitted by statutory regulation or exceeds the permitted use, you will need to obtain permission directly from the copyright holder. To view a copy of this licence, visit http://creativecommons.org/licenses/by/4.0/.

\section{References}

Abrahamsson L (2000) Att återställa ordningen. Umeå: Borea Bokförlag Abrahamsson L, Johansson J (2006) From grounded skills to sky qualifications. J Ind Relat 48(5)

Abrahamsson L, Somerville M (2007) Changing storylines and masculine bodies in Australian coal mining organisations. Nordic J Masc Stud 2(1):52-69

Abrahamsson L, Johansson B, Johansson J (2009) Future of metal mining: sixteen predictions. IJMME 1(3):304-312

Abrahamsson L (2014) Gender and the modern organization, ten years after. Nordic J Work life Stud 4(4):109-136

Abrahamsson L, Segerstedt E, Nygren M, et al (2014) Mining and sustainable development: gender, diversity and work conditions in mining. Luleå: Luleå Tekniska Universitet

Abrahamsson L, Lööw J, Nygren M, et al (2016) Challenges in obtaining asocial license to mine. AusIMM Bulletin

Acker J (1992) Gendering organizational theory. In: Mills AJ, Tancred P (eds) Gendering organizational analysis. Sage, Newbury Park, pp 248-260

Ackroyd S, Crowdy P (1990) Can culture be managed? Working with raw material: the case of the English slaughterhouse workers. Pers Rev 19(5):3-14

Andersson E (2012) Malmens manliga mysterium [The male mystery of mining]. Doctoral thesis, Luleå University of Technology

Andersson,E, Abrahamsson L (2007) Deep down, a change of attitude makes a difference! Experiences from a project on work safety and masculinity at LKAB. Paper at the Swedish Production Symposium, 28-30 Aug 2007, Göteborg

Ashcraft KL (2005) Resistance through consent? Occupational identity, organizational form, and the maintenance of masculinity among commercial airline pilots. Manag Commun Q 19(1):67-90

Blomberg E (2006) Gender relations in iron-mining communities in Sweden, 1900-1940. In: Mercier L, Gier J (eds) Mining women: gender in the development of a global industry, 1670-2005. Palgrave Macmillan, New York, pp 119-135

Bryant L, Jaworski K (2011) Gender, embodiment and place. Hum Relat 64:1345

Collinson DL (1988) 'Engineering humour': masculinity, joking and conflict in shopfloor relations. Organ Stud 9(2):181-199

Collinson D (1992) Managing the shopfloor: subjectivity, masculinity and workplace culture. Walter de Gruyter, Berlin

Collinson D, Ackroyd S (2005) Resistance, misbehaviour, and dissent. In: Ackroyd et al (eds) The Oxford handbook of work and organization. Oxford University Press, Oxford

Connell RW (1995) Masculinities. University of California Press, Berkeley

Deutsch FM (2007) Undoing gender. Gend Soc 21(1):106-127

Ely, R.J. and Meyerson, D. (2000). Theories of gender in organizations: a new approach to organizational analysis and change. Res Organ Behav 22:103-151

Ely RJ, Meyerson D (2008) Unmasking manly men. Harward Bus Rev

Ely, R.J. and Meyerson, D. (2010). An organisational approach to undoing gender. Res Organ Behav 20:3-34

Eveline J (1989). Patriarchy in the diamond mines. Unpublished Honours thesis, Murdoch University, Australia

Eveline, J. (2001). "Keeping the boys happy": managerialism and the resistance of women miners in Australia. Unpublished paper, Gender, Work and Organization Conference, University of Keele, UK

Eveline J, Booth M (2002) Gender and sexuality in discourses of managerial control: the case of women miners. Gend Work Organ 9(5)

Fältholm Y (1998) Work, cooperation and professionalization, Doctoral thesis, Luleå University of Technology 
Fältholm Y, Abrahamsson L (2015) Cracks in the workers' collective windows for change towards gender equal mining workplaces. Paper and presentation at The 33rd International Labour Process Conference, Athens, April 13-15, 2015

Gherardi S, Nicolini D (2000) The organizational learning of safety in communities of practice. J Manag Inq 9(1):7-18

Johansson J (1986) Teknisk och organisatorisk gestaltning - Exemplet $L K A B$, Doctoral thesis 1986:52D, Luleå University of Technology, Luleå: CENTEK förlag

Johansson B, Johansson J, Abrahamsson L (2010) Attractive workplaces in the mine of the future: 26 statements. Int J Min Miner Eng 2(3): $239-252$

Johansson M, Ringblom L (2017) The business case of gender equality in Swedish forestry and mining: restricting or enabling organizational change. Gend Work Organ 24(6):628-642

Johansson K, Andersson E, Johansson M, et al (2017) The discursive resistance of men to gender equality interventions. Men Masculinities 22(2):177-196

Kagerman H, Wahlster W, Helbig J (2013) Recommendations for implementing the strategic initiative Industrie 4.0. Acatech, München

Kanter RM (1977) Men and women of the corporation. Basic books, New York

Karlsson JCh (2011) Organizational misbehavior in the workplace. Narratives of Dignity and Resistance, London: Palgrave Macmillan

Kelan E (2018) Men doing and undoing gender at work: a review and research agenda. Int J Manag Rev 20:544-588

Kern, H. and Schumann, M. (1974). Industriearbeit und Arbeiterbewusstsein, (EVA) Frankfurt am Main/Köln

Lahiri-Dutt K (2007) Roles and status of women in extractive industries in India. Social Chang 37:37

Lahiri-Dutt K (2011) The megaproject of mining: a feminist critique. In: Brunn SD (ed) Engineering earth: the impacts of megaengineering projects. Springer Netherlands, Dordrecht

Lahiri-Dutt K (2012) Digging women: towards a new agenda for feminist critiques of mining. Gend Place Cult 19(2):193-212

Lahiri-Dutt K (2013) Gender (plays) in Tanjung Bara mining camp in Eastern Kalimantan, Indonesia. Gend Place Cult 20(8):979-998

Lahiri-Dutt K, Macintyre M (2006) Where life is in the pits (and elsewhere) and gendered. In: Lahiri-Dutt K, Macintyre M (eds) Women Miners in Developing Countries: Pit Women and Others. Ashgate publishing, pp 1-22

Laplonge D (2011) Toughness in the workplace. The Department of Mines and Petroleum, Perth

Laplonge D (2014a) So you think you're tough? Getting serious about gender in mining. Factive, Perth

Laplonge D (2014b) Telling tales of safety to men in mining. J Health Saf Environ 30(3):300-322

Laplonge D (2016) Exploring the distance between ecofeminism and Women in Management (WIM). Extr Ind Soc 3(2016):843-849

Laplonge D (2017) The "un-womanly" attitudes of women in mining towards the environment. Extr Ind Soc 4(2):304-309

Lasi H, Fettke PDP, Kemper HG, Feld DIT, Hoffmann DHM (2014) Industry 4.0. Bus Inf Syst Eng 6(4):239-242

Lindgren G (1985) Kamrater, kollegor och kvinnor [Mates, colleagues and women]. Umeå: Sociologiska institutionen, Umeå universitet

Linstead S, Maréchal G, Griffin RW (2014) Theorizing and researching the dark side of organization. Organ Stud 35(2):165-188

Lööw J (2015) Lean production in mining: an overview, Research report, Luleå University of Technology

Lorber J (2000) Using gender to undo gender: a feminist degendering movement. Fem Theory 1:79

Lysgaard S (1961) Arbeiderkollektivet [The workers collective], Oslo: Universitetsforlaget
Macdonald C (2017) The role of gender in the extractives industries. WIDER Working Paper 2017/52, UNU-WIDER 2017

Mayes R, Pini B (2010) The 'feminine revolution in mining': a critique. Aust Geogr 41(2):233-245

Mayes R, Pini B (2014) The Australian mining industry and the ideal mining woman: mobilizing a public business case for gender equality. J Ind Relat 56(4):527-546

Mellström U (2004) Machines and masculine subjectivity, technology as an integral part of men's life experiences. Men and Masculinities Special Issue: Masculinities and Technology 6(4):368-383

Mercier L, Gier J (ed) (2006) Mining women: gender in the development of a global industry. New York: Palgrave Macmillan

Meyerson D, Kolb D (2000) Moving out of the 'armchair'. Developing a framework to bridge the gap between feminist theory and practice. Organization 7(4):553-571

Norberg C, Fältholm Y (2018) "Learn to blend in!”: a corpus-based analysis of the representation of women in mining. Equal Divers Incl 37(7):698-712

Olofsson J (2010) Taking place - augmenting space: spatial diffusion in times of technological change. Doctoral thesis, Luleå University of Technology, Luleå

Ringblom L (2019) Utmanad ordning? En studie av kön och jämställdhetsarbete $i$ den svenska gruvindustrins arbetsorganisationer [Challenging the gendered order? A study of gender and gender equality work in the Swedish mining industry]. Doctoral thesis, Luleå University of Technology, Luleå

Ringblom L, Abrahamsson L (2017) Omförhandling i gruvan? Om kön, arbete och förändring i den mansdominerade gruvnäringen. Tidskrift för Genusvetenskap 38(1-2):33-54

SIP-Strim (2019) Strategic research and innovation roadmap for the Swedish mining. Mineral and Metal Producing Industry

Somerville M (2005) Working culture: expanding notions of workplace cultures and learning at work. Pedagog Cult Soc 13(1):5-27

Somerville M, Abrahamsson L (2003) Trainers and learners constructing a community of practice: masculine work cultures and learning safety in the mining industry. Stud Educ Adults 35(1):19-34

Somerville M, Lloyd A (2006) Codified knowledge and embodied learning: the problem of safety training. Stud Contin Educ 28(3):279-289

Stenbacka S (2011) Othering the rural: About the construction of rural masculinities and the unspoken urban hegemonic ideal in Swedish media. J Rural Stud 27(3):235-244

Swedish Government Offices of Sweden (2013). Sweden's minerals strategy for sustainable use of Sweden's mineral resources that creates growth throughout the country. Report from Ministry of Enterprise and Innovation

Tallichet SE (2000) Barriers to women's advancement in underground coal mining. Rural Sociol 65(2):234-252

Tallichet SE (2006) Daughters of the mountain - women coal miners in Central Appalachia. Penn State University Press

Wajcman J (1991) Feminism confronts technology. Polity Press, Cambridge

Whitehead SM (2002) Men and masculinities. Polity Press, Cambridge

Wicks D (2002) Institutional base of identity construction and reproduction: the case of underground coal mining. Gend Work Organ 9:3

Willis P (1977) Learning to labour. Saxon House, London

Yount K (1991) Ladies, flirts and tomboys: strategies for managing sexual harassment in an underground coal mine. J Contemp Ethnogr 19(4): $396-422$

Publisher's note Springer Nature remains neutral with regard to jurisdictional claims in published maps and institutional affiliations. 